University of Nebraska - Lincoln

DigitalCommons@University of Nebraska - Lincoln

Michigan Bovine Tuberculosis Bibliography and

Database

Wildlife Disease and Zoonotics

2010

\title{
Emergence of Diseases From Wildlife Reservoirs
}

J. C. Rhyan

National Wildlife Research Center, Fort Collins, CO, USA

T. R. Spraker

Colorado State University, Fort Collins, CO, USA

Follow this and additional works at: https://digitalcommons.unl.edu/michbovinetb

Part of the Veterinary Medicine Commons

Rhyan, J. C. and Spraker, T. R., "Emergence of Diseases From Wildlife Reservoirs" (2010). Michigan Bovine Tuberculosis Bibliography and Database. 103.

https://digitalcommons.unl.edu/michbovinetb/103

This Article is brought to you for free and open access by the Wildlife Disease and Zoonotics at DigitalCommons@University of Nebraska - Lincoln. It has been accepted for inclusion in Michigan Bovine Tuberculosis Bibliography and Database by an authorized administrator of DigitalCommons@University of Nebraska Lincoln. 


\title{
Emergence of Diseases From Wildlife Reservoirs
}

Veterinary Pathology

47(I) 34-39

(C) The American College of

Veterinary Pathologists 2010

Reprints and permission: http://www. sagepub.com/journalsPermissions.nav DOI: $10.1177 / 0300985809354466$ http://vet.sagepub.com

@SAGE

\section{J. C. Rhyan, and T. R. Spraker}

\begin{abstract}
Interest in the epidemiology of emerging diseases of humans and livestock as they relate to wildlife has increased greatly over the past several decades. Many factors, most anthropogenic, have facilitated the emergence of diseases from wildlife. Some livestock diseases have "spilled over" to wildlife and then "spilled back" to livestock. When a population is exposed to an infectious agent, depending on an interaction of factors involving the host, agent, and environment, the population may be resistant to infection or may become a dead-end host, a spillover host, or a maintenance host. Each exposure is unique; the same species of host and agent may respond differently in different situations. Management actions that affect the environment and behavior of a potential host animal may allow the emergence of a new or as yet undetected disease. There are many barriers in preventing, detecting, monitoring and managing wildlife diseases. These may include political and legal hurdles, lack of knowledge about many diseases of wildlife, the absence of basic data on wildlife populations, difficulties with surveillance, and logistical constraints. Increasing interaction between wildlife and humans or domestic animals may lead to disease emergence and require innovative methods and strategies for disease surveillance and management in wildlife.
\end{abstract}

\section{Keywords}

emerging diseases, wildlife, wildlife reservoirs, zoonotic diseases, surveillance, disease management

To keep every cog and wheel is the first precaution of intelligent tinkering.-Aldo Leopold

Three fourths of all emerging infectious diseases of humans are zoonotic; most originate in wildlife, and their incidence since 1940 has increased. ${ }^{15,34}$ Wildlife can also serve as vectors for nonzoonotic diseases of livestock, potentially devastating to human populations not only economically but, in many regions, in terms of the resulting loss of human dietary protein.

Wildlife reservoirs have long been recognized for several important zoonotic diseases, including plague, rabies, and tularemia. Other diseases of livestock such as tuberculosis and brucellosis likely were transmitted or "spilled over" to native wildlife species and recently have "spilled back" to livestock. The frequency of emergence and reemergence of infectious diseases in wildlife reservoirs has recently appeared to increase, posing new questions about disease pathogenesis and epidemiology and heightening the urgency of finding effective wildlife disease management techniques. This apparent increased involvement of wildlife in livestock and human disease is likely due to several changing factors, most of them anthropogenic. These anthropogenic factors generally fit into 2 related categories: human encroachment into wildlife habitat, and increasing interest in and popularity of wildlife. The heightened interest has likely led to better disease surveillance in wildlife, resulting in more disease detection, although the increase in disease detection is arguably an artifact of the enhanced monitoring. On the other hand, increased wildlife popularity has also led to more transport of wildlife and wildlife products, more human contact with wildlife, the development of wildlife-associated and captive wildlife industries, and more intensive management of selected species that may precipitate increased animal density and resultant behavioral changes. Together with the encroachment of humans and their domestic animals on ever more fragmented wildlife habitats, all these factors increase the potential for dramatically altering the frequency, duration, and intensity of many interfaces, including those among wildlife species and other free-living or captive wildlife, domestic animals and humans. These interfaces may be direct, through interspecies contact, or indirect, through shared space or vectors. They may also be multidirectional, as in intraspecific transmission of brucellosis in bison and elk populations in the greater Yellowstone area (GYA), with occasional interspecies transmission also involving cattle, horses, and humans. ${ }^{4}$ Another kind of interface is created with the deliberate or accidental introduction of

\footnotetext{
'National Wildlife Research Center, Fort Collins, CO, USA

${ }^{2}$ Colorado State University, Fort Collins, CO, USA

Corresponding Author:

J. C. Rhyan, 4I0I LaPorte Ave, Fort Collins, CO 8052I, USA

Email: jack.c.rhyan@aphis.usda.gov
} 
nonnative animals into areas already containing high population densities. The recent outbreak of monkeypox in humans in the USA is a good example of an infection acquired at the interface created by increased transport of exotic animals and the public's interest in nontraditional pets. ${ }^{3}$ That outbreak resulted from exposure of humans to pet prairie dogs that had acquired the monkeypox infection, while in commercial channels, from rodents imported from Ghana. Changing agricultural practices produced another outbreak of zoonotic disease, Nipah virus infection, in Malaysia in 1998-1999. ${ }^{8}$ Deforestation and intensive fruit tree cultivation combined with increased pig farming to elevate the exposure of pigs to fruit bats subclinically infected with and shedding Nipah virus. The virus rapidly spread through the country's pig population, certainly through trade and possibly also between farms by dogs and cats. Humans in direct contact with pigs then acquired the infection and its often-fatal encephalitis. Several recent articles examine these and other examples and their predisposing causes. ${ }^{5,9,16,18,40}$

The many difficulties in the surveillance and management of emerging diseases in wildlife are at the same time exciting opportunities to develop effective strategies and methods to address those difficulties. Our purposes in this article are to describe several concepts that help us understand disease emergence in wildlife; to review some of the difficulties of surveillance and management of emerging diseases in wildlife; and to identify a few current and potential strategies and techniques for detecting, monitoring, containing, eliminating, and preventing emerging diseases in wildlife.

\section{Concepts in Understanding the Role of Wildlife in Emerging Diseases}

When a pathogen enters a new species, many host, agent, and environmental factors influence the outcome, and these factors may interact in unforeseen ways. These interactions determine whether the species is resistant to infection; is a "dead-end" host, not able to maintain the infection without an external source; is a "spillover" host, able to maintain the infection for a time but requiring periodic input from another source; or is a maintenance host, able to maintain infection without further transmission from another species. Both maintenance and, in some circumstances, spillover hosts may become disease vectors, transmitting infection to other species. The most epidemiologically significant species are maintenance hosts capable of interspecific disease transmission.

Animal health workers often categorize animals neatly as wildlife, domestic animals, and zoo animals, with accompanying naive notions such as "wildlife are usually healthy because of natural selection" or "wildlife are usually the reservoirs of livestock diseases." Rather, it is more helpful to consider all animals as animal populations, each with unique behaviors, dietary needs, and disease susceptibilities, influenced by various types of management. In managing wildlife populations, we often make the mistake of adding components of intensive management such as fencing, supplemental feeding, or the introduction of animals from other populations without taking ramifications into account. These may include increased animal density, which results in behavioral changes that facilitate disease transmission and require mitigating actions such as vaccination and parasite control to avoid disease outbreaks. An example of this occurred in the northeastern counties of lower Michigan during the 20th century, when free-ranging white-tailed deer, spillover hosts of bovine tuberculosis in most situations, became maintenance hosts with spillback to cattle herds when management changes increased population densities and increased exposure as deer congregated at feed sites. Since the 1920s there have been rare reports of tuberculosis in white-tailed deer, usually in proximity to infected cattle herds, but the disease did not become endemic in those populations and white-tailed deer were considered a spillover host for Mycobacterium bovis infection. Large land purchases by individuals and hunt clubs beginning in the late 19th century restricted commercial and public hunting in Michigan, however. ${ }^{28}$ This created a refuge effect, allowing an increasing deer population that by the 1930s exceeded the carrying capacity of the habitat. At that point, individuals and hunt clubs implemented supplemental feeding, which soon became a common practice. In the 1940s through the 1960s, some hunt clubs also ran cattle on their land. In the 1980s and 1990s, supplemental feeding increased dramatically, some hunt clubs constructed fences to limit migration, and deer were imported from other areas for genetic improvement. $M$ bovis infection, first discovered in a single deer in 1975, likely was amplified by the high deer densities and the congregation of deer at feed sites until it was rediscovered in 1994 and changes in management were implemented.

Especially in wildlife, additive factors or conditions may synergistically precipitate an outbreak, like adding bags of sand to a rowboat until it sinks. Which sandbag sank the boat? In diagnostic medicine the last 1 or 2 "sandbags" are usually identified as causes, but other factors may be unknown and ignored, such as underlying nutritional deficiencies due to a recent drought or the heavy winter tick load of 3 months prior. Other stressors such as loss of habitat, higher animal density, or increased predation may also contribute to disease emergence. These underlying factors sometimes relegate wildlife to the role of a miner's canary, manifesting and/or amplifying an otherwise unrecognized or smoldering infection and perhaps causing spillback to livestock, as was the case in the $M$ bovis-infected Michigan deer or the emergence of a new zoonosis such as the transmission of Nipah virus from the increased fruit bat population to the increased pig population and then to humans.

Variation in underlying predisposing factors may account for varying outcomes of infection in different populations of a potential wildlife disease reservoir species. Feral swine in Australia were considered a spillover host of $M$ bovis with little risk of transmission to cattle. Following eradication of the disease in cattle and buffalo, surveillance in feral swine revealed almost no tuberculosis. ${ }^{21}$ On the Hawaiian island of Molokai, the prevalence of tuberculosis in feral swine also declined 
dramatically with the elimination of the infection in cattle. However, even after depopulation of cattle on the island, the disease was maintained at a low prevalence in the swine with at least 1 known spillback into reintroduced cattle. ${ }^{12,13,36}$ In areas of southern Spain and France, the conspecific wild boar appears to be a maintenance host for bovine tuberculosis and is considered a potential wildlife reservoir of the disease for cattle and domestic swine. ${ }^{26,42}$ Prevalence increased in France even after the disease was eliminated from livestock.

For poorly understood reasons, avenues of infection as well as prevalence may vary among populations. Feral swine in Australia routinely had gastrointestinal lesions of $M$ bovis infection, suggestive of ingestion as a portal of entry, whereas in Molokai and Spain feral swine and wild boar have a high percentage of thoracic lesions, suggesting predominantly aerosol transmission. ${ }^{12,21,26}$ Unspecified environmental, hostrelated, and/or agent-related differences have apparently resulted in varying outcomes of host status (spillover vs maintenance) and pathogenesis (oral vs aerosol exposure) in these 3 wild pig $M$ bovis infections (Australia, Molokai, and Europe).

Behavioral interactions can also greatly influence disease outcome in animal populations. Excellent examples include tuberculosis in cattle, red deer, and brush-tailed possums in New Zealand and in European badgers and cattle in the UK. Badgers and possums, terminally ill with tuberculosis, have atypical behaviors including loss of fear toward cattle and deer. When curious cattle or deer investigate the unusual approaching animals, the ungulates are exposed to large doses of $M$ bovis. ${ }^{7,24,32}$ Specific individual cattle predominate in interaction with badgers and may act as hubs in the interspecific contact network. ${ }^{2}$ Similarly, individual red deer, based on curiosity and social ranking, investigate infected possums. ${ }^{19}$

Animal behavioral changes in response to management actions may also profoundly affect the epidemiology of interface diseases, for example, the differing outcomes of Brucella abortus infection in free-ranging bison and elk populations in the GYA. $B$ abortus is transmitted chiefly through contact with aborted fetuses, placental membranes, or infectious vaginal discharge. Bison often calve with other herd members in close proximity, and calving events attract the attention of other cows and calves, with licking and sniffing of the fetal membranes and neonate around parturition. This behavior is especially marked early in the calving season and diminishes later after most animals have calved. ${ }^{29}$ In contrast, elk usually calve in seclusion, are fastidious in consuming the placenta and cleaning the calving site, and keep the calf isolated from the herd for several days or weeks following parturition. ${ }^{35}$ This behavioral difference between the bison and elk probably explains the maintenance host role of bison and the absence of brucellosis in most elk populations in North America. ${ }^{1,4,6}$ In southern portions of the GYA, however, approximately 23,000 elk receive supplemental feed on state and federal feedgrounds, ${ }^{20} \mathrm{a}$ mitigation strategy designed to keep elk from seeking cattle feedlines. The winter feeding maintains increased density of elk above the natural carrying capacity of the habitat, however, and feeding grounds provide a site for elk to congregate daily with increased exposure to infectious abortions and discharge on feedstuffs. The prevalence of brucellosis is markedly increased in the elk that receive supplemental feed, with a resulting increased risk of transmission to bison that share feeding grounds and to cattle in the area. B. abortus is absent from free-ranging elk populations established from GYA herds in the mid-20th century, in contrast to a herd established in New Mexico from GYA elk. The New Mexico herd received supplemental feed and was a maintenance host for B. abortus until the disease was eradicated using management changes and test and slaughter (Watts and Francisco, unpublished).

Change precipitates change. As diagnosticians, we see the consequence of change in the form of an emerging disease. But when a disease emerges in wildlife, recent alterations in the environment need to be considered. We may also be seeing the consequences of ecologic modifications such as deforestation or reforestation, changes in farming practices or grazing strategies, ${ }^{25}$ or introductions of nonnative species or the same species from a different location. Management adjustments of the involved species or other species within the ecosystem may contribute to disease emergence, as well as other stressors including weather, increased population densities, underlying diseases or nutritional deficiencies, predation or habitat destruction, or fragmentation. When animals are translocated into a new environment, not just a single species is being introduced but rather an entire micro-ecosystem consisting of the target species and all its accompanying microbes and parasites. Any significant change occurring in the environment and management of the population, or even other populations in the same ecosystem, may imbalance the equilibrium of the host, agent, and environment, allowing a newly introduced agent or subclinical infection to manifest as an emerging disease.

\section{Difficulties of Surveillance and Management of Diseases in Wildlife}

The science-related difficulties often pale in comparison to the political difficulties in attempting disease surveillance and management in wildlife. Overcoming these difficulties usually requires great efforts in interagency team building (biologists and animal and public health investigators and authorities) with involvement and education of the public. Indeed, when tackling an emerging disease issue in wildlife, competent, energized, and proactive public affairs specialists are as important as wildlife and animal health professionals. These public affairs specialists must have a thorough understanding of the disease situation and needed management actions and must be able to communicate them to the public in public meetings and via the media. In some situations these specialists must work with animal and public health officials to plan and execute an active campaign of public education based on current science and avoid reacting defensively to rumor and misinformation. It is imperative to include these public affairs specialists in the core team of individuals involved in an emerging disease issue in wildlife. 
Technical difficulties often include the lack of any baseline data on the disease and population in question. For many wildlife populations, obtaining a census or even reliable estimate of the population is problematic. ${ }^{41}$ A recent modeling exercise showed that the likelihood of infectious disease emergence in an area varies inversely with the level of resources allocated for surveillance: the more surveillance, the less the chance of disease emergence. Conversely, the most substantial risk of emergence of wildlife zoonotic and vector-borne disease is in lower latitudes where reporting effort is low. ${ }^{15}$ Passive surveillance requires the observation of clinically diseased or dead animals or the opportunistic collection of specimens. Passive surveillance methods often depend on the public to report sick or dead animals but can also consist of routine collection of hunter-killed samples and collection of road-kill animals. Survival behaviors often mask clinical signs of disease in wildlife. For example, bison with severe foot-and-mouth disease (FMD) display marked stoicism, making the detection of affected animals more difficult. ${ }^{30}$ Predation and scavenging of wildlife may obscure the observation of dead animals and usually complicate the diagnostic process when carcasses are found.

Active disease surveillance in wildlife requires the capture or killing of animals for specimen collection with traps, sharpshooters, net guns, drive nets, hazing, chemical immobilization, and other methods. All these methods are invasive to the environment and may result in the rapid dispersal of animals infected with an emerging disease. Planners avoided the dispersal problem during early wildlife surveillance in the 1924-1925 FMD outbreak that spilled over from cattle into mule deer in the Stanislaus National Forest in California by placing strychnine-laced salt in salt feeders distributed in the forest for cattle but also used by wildlife. ${ }^{17}$ The technique was effective but today might encounter insurmountable political and legal hurdles stemming from concerns over humane treatment and impacts on nontarget species.

Another difficulty in emerging disease surveillance and management in wildlife is a lack of basic knowledge concerning many diseases in wild species. The diagnostician is presented not only with an unfamiliar disease but with an animal species for which there is little or no information. Such basic parameters as susceptibility, carrier status, and transmission potential are unknown for many diseases in wildlife species. Planners and modelers are often forced to extrapolate from knowledge in other species when they try to consider the wildlife factor, especially when foreign animal diseases are involved. This can lead to erroneous conclusions and surprises. For example, experimentally, FMD virus type $\mathrm{O}$ is both highly pathogenic and transmissible in bison, pronghorn, white-tailed deer, and mule deer but not in elk. ${ }^{22,30}$ In each emerging disease situation, every effort should be made to understand the pathogenesis and epidemiology of the disease in the species at risk including unique behavioral and environmental factors. Extrapolation from other species and environments is often the best we can do but should not be considered adequate in a thorough disease investigation or disease planning exercise.
Factual information for the disease must continually be sorted from speculation based on data from other diseases or species.

Finally, the logistical problems of conducting disease surveillance and management in wildlife are often difficult to overcome. Making accurate population estimates, accomplishing effective disease containment, using efficacious vaccination, and even achieving complete depopulation of a wildlife species in a given area are extremely difficult if not impossible in a wild setting.

\section{Current and Potential Techniques for Disease Management in Wildlife}

The current difficulties in disease prevention, surveillance, and management in wildlife present challenging opportunities demanding innovation based on solid scientific evidence. The goal is to develop efficacious ways to accomplish in wildlife the standard animal disease management practices of vaccination, therapy, quarantine, surveillance, test and slaughter, or depopulation when needed. Remote rabies vaccination of canids in Europe and the USA has been very successful in containing that zoonotic disease in wildlife. Strategically placed vaccinia-based oral vaccine has contained the spread of rabies in some wild canid populations. ${ }^{33}$ Firing vaccine-filled polymer bullets from air guns to vaccinate elk on feeding grounds has not had the desired results of eliminating brucellosis from feeding-ground elk, likely because of the poor efficacy of the vaccine in elk. ${ }^{4}$ The technique does demonstrate a method for remote parenteral vaccination of wildlife that might be effective in another setting, however. ${ }^{31}$

Investigators are developing other disease detection and containment techniques and ways to mitigate problems arising from interspecies contact at the interface of wildlife and domestic animals. ${ }^{41}$ These include using sentinel animals, ${ }^{27}$ scare devices, ${ }^{14}$ repellents, specialized fencing and gates, ${ }^{38,39}$ trained dogs,${ }^{37}$ and rapidly installed or virtual fencing to immediately restrict animal movement. Immunocontraception can prevent transmission of venereal diseases and diseases spread by abortion. ${ }^{23}$ Infrared imaging has been an effective disease surveillance tool in some situations, for example, as a screening tool for rabies in raccoons and FMD in ungulates. ${ }^{10,11}$ Work is beginning on the use of temporary feed stations for feral swine. The stations may minimize migration, allow scientists to conduct remote disease surveillance through infrared imaging, and permit administering vaccines, therapeutics, or toxicants for disease management.

\section{Conclusion}

As the various interfaces between wildlife, domestic animals, and humans increase and become more complex, we can anticipate increased involvement with wildlife in emerging diseases. This underscores the need for increased disease surveillance in wildlife and calls urgently for the development of novel, effective methods for surveillance, management, and prevention of disease in wild populations as well as better mitigation 
strategies to prevent disease transmission at these interfaces. More interdisciplinary collaboration is needed, not only among wildlife biologists and health professionals but with animal behaviorists, biomedical engineers, and others. The emergence of diseases in wildlife challenges us to an exciting 2-fold mission. We must develop, test, and use more effective disease surveillance and management practices in wildlife, and we must also maintain healthy, native animal populations in the wild. These objectives are not mutually exclusive. Instead, they must be mutually embracing.

\section{Declaration of Conflict of Interest}

The authors declared that they had no conflicts of interests with respect to their authorship or the publication of this article.

\section{Financial Disclosure/Funding}

The authors declared that they received no financial support for their research and/or authorship of this article.

\section{References}

1. Aguirre AA, Hansen DE, Starkey EE, McLean RG: Serologic survey of wild cervids for potential disease agents in selected national parks in the United States. Prevent Vet Med 21:313322, 1995.

2. Bohm M, Hutchings MR, White PCL: Contact networks in a wildlife-livestock host community: identifying high-risk individuals in the transmission of bovine TB among badgers and cattle. PLoS ONE 4:e5016, 2009.

3. Centers for Disease Control and Prevention. Update: multistate outbreak of monkeypox-Illinois, Indiana, Kansas, Missouri, Ohio, and Wisconsin, 2003. MMWR Morb Mort Wkly Rep 52:642-646, 2003.

4. Cheville NF, McCullough DR, Paulson LR: Brucellosis in the Greater Yellowstone Area. National Research Council, National Academy of Sciences, pp. 42-106. National Academy Press, Washington, DC, 1998.

5. Chomel BB, Belotto A, Meslin F-X: Wildlife, exotic pets, and emerging zoonoses. Emerg Infect Dis 13:6-11, 2007.

6. Conner MM, Ebinger MR, Blanchong JA, Cross PC: Infectious disease in cervids of North America. Ann NY Acad Sci 1134:146-172, 2008.

7. Corner LAL: The role of wild animal populations in the epidemiology of tuberculosis in domestic animals: how to assess the risk. Vet Microbiol 112:303-312, 2006.

8. Daszak P, Cunningham AA, Hyatt AD: Anthropogenic environmental change and the emergence of infectious diseases in wildlife. Acta Trop 78:103-116, 2001.

9. Daszak P, Cunningham AA, Hyatt AD: Emerging infectious diseases of wildlife-threats to biodiversity and human health. Science 287:443-449, 2000.

10. Dunbar MR, Johnson SR, Rhyan JC, McCollum M: Use of infrared thermography to detect thermographic changes in mule deer (Odocoileus hemionus) experimentally infected with foot-andmouth disease. J Zoo Wildl Med 40:296-301, 2009.
11. Dunbar MR, MacCarthy K: Use of infrared thermography to detect signs of rabies infection in raccoons (Procyon lotor). J Zoo Wildl Med 37:518-523, 2006.

12. Essey MA, Payne RL, Himes EM, Luchsinger D: Bovine tuberculosis surveys of axis deer and feral swine on the Hawaiian island of Molokai. In: Proceedings of the 85th Annual Meeting of the US Animal Health Association; October 11-16 1981; St Louis, MO; pp. 538-549.

13. Essey MA, Stallknecht DE, Himes EM: Follow-up survey of feral swine for Mycobacterium bovis infection on the Hawaiian island of Molokai. In: Proceedings of the 87th Annual Meeting of the US Animal Health Association; October 16-21 1983; Las Vegas, NV; pp. 589-595.

14. Gilsdorf JM, Hygnstrom SE, VerCauteren KC: Use of frightening devices in wildlife damage management. Integr Pest Manage Rev 7:29-45, 2002.

15. Jones KE, Patel NG, Levy MA, Storeygard A, Balk D, Gittleman JL, Daszak P: Global trends in emerging infectious diseases. Nature 451:990-993, 2008.

16. Karesh WB, Cook RA, Bennett EL, Newcomb J: Wildlife trade and global disease emergence. Emerg Infect Dis 11:1000-1002, 2005.

17. Keane C. The outbreak of foot and mouth disease among deer in the Stanislaus National Forest. California Department of Agriculture Monthly Bulletin 16:213-226, 1927.

18. Kuiken T, Leighton FA, Fouchier RAM, LeDuc JW, Peiris JSM, Schudel A, Stöhr K, Osterhaus ADME: Pathogen surveillance in animals. Science 309:1680-1681, 2005.

19. Lugton IW, Wilson PR, Morris RS, Griffin JF, de Lisle GW: Natural infection of red deer with bovine tuberculosis. $\mathrm{N} Z$ Vet $\mathrm{J}$ 45:19-26, 1997.

20. Maichak EJ, Scurlock BM, Rogerson JD, Meadows LL, Barbknecht AE, Edwards WH, Cross PC: Effects of management, behavior, and scavenging on risk of brucellosis transmission in elk of western Wyoming. J Wildl Dis 45:398-410, 2009.

21. McInerney J, Small KJ, Caley P: Prevalence of Mycobacterium bovis infection in feral pigs in Northern Territory. Aust Vet $\mathrm{J}$ 72:448-451, 1995.

22. McVicar JW, Sutmoller P, Ferris DH, Campbell CH: Foot-andmouth disease in white-tailed deer: clinical signs and transmission in the laboratory. In: Proceedings of the 78th Annual Meeting of the US Animal Health Association; October 13-18 1974, Roanoke, VA; pp. 169-180.

23. Miller LA, Rhyan JC, Drew M: Contraception of bison by GnRH vaccine: a possible means of decreasing transmission of brucellosis in bison. J Wildl Dis 40:725-730, 2004.

24. Muirhead RH, Gallagher J, Burn KJ: Tuberculosis in wild badgers in Gloucestershire: epidemiology. Vet Rec 95:552-555, 1974.

25. Munyeme M, Muma JB, Samui KL, Skjerve E, Nambota AM, Phiri IGK, Rigouts L, Tryland M: Prevalence of bovine tuberculosis and animal level risk factors for indigenous cattle under different grazing strategies in the livestock/wildlife interface areas of Zambia. Trop Anim Health Prod 41:345-352, 2009.

26. Naranjo V, Gortazar C, Vicente J, de la Fuente J: Evidence of the role of European wild boar as a reservoir of Mycobacterium tuberculosis complex. Vet Microbiol 127:1-9, 2008. 
27. Nugent G, Whitford J, Young N: Use of released pigs as sentinels for Mycobacterium bovis. J Wildl Dis 38:665-677, 2002.

28. O'Brien DJ, Schmitt SM, Fitzgerald SD, Berry DE, Hickling GJ: Managing the wildlife reservoir of Mycobacterium bovis: The Michigan, USA, experience. Vet Microbiol 112:313-323, 2006.

29. Rhyan JC: Brucellosis in terrestrial wildlife and marine mammals. In: Emerging Diseases of Animals, eds. Brown C and Bolin C, pp. 161-184. ASM Press, Washington, DC, 2000.

30. Rhyan JC, Deng M, Wang H, Ward G, Gidlewski T, McCollum M, Metwally S, McKenna T, Wainwright S, Ramirez A, Mebus C, Salman M: Foot-and-mouth disease in North American bison (Bison bison) and elk (Cervus elaphus nelsoni): susceptibility, intra- and interspecies transmission, clinical signs, and lesions. J Wildl Dis 44:269-279, 2008.

31. Roffe TJ, Jones LC, Coffin K, Drew ML, Sweeney SJ, Hagius SD, Elzer PH, Davis D: Efficacy of single calfhood vaccination of elk with Brucella abortus strain 19. J Wildl Manage 68:830-836, 2004.

32. Sauter CM, Morris RS: Dominance hierarchies in cattle and red deer (Cervus elaphus): their possible relationship to transmission of bovine tuberculosis. N Z Vet J 43:301-305, 1995.

33. Slate D, Rupprecht CE, Rooney JA, Donovan D, Lein DH, Chipman RB: Status of oral rabies vaccination in wild carnivores in the United States. Virus Res 111:68-76, 2005.
34. Taylor LH, Latham SM, Woolhouse MEJ: Risk factors for human disease emergence. Phil Trans R Soc Lond B 356:983-989, 2001.

35. Thorne ET: Brucellosis. In: Infections Diseases of Wild Mammals, eds. Williams ES and Barker IK, 3rd ed., pp. 372-395. Iowa State University Press, Ames, Iowa, 2001.

36. Thompson D: Report of the Committee on Tuberculosis. In: Proceedings of the 103rd Annual Meeting of the US Animal Health Association; 1999; October 7-14 San Diego, CA; pp. 594-607.

37. VerCauteren KC, Lavelle MJ, Phillips GE: Livestock protection dogs for deterring deer from cattle and feed. J Wildl Manage 72:1443-1448, 2008.

38. VerCauteren KC, Seward NW, Lavelle MJ, Fischer JW, Phillips GE: Deer guards and bump gates for excluding white-tailed deer from fenced resources. Hum Wildl Conflicts 3:145-153, 2009.

39. VerCauteren KC, Seward NW, Lavelle MJ, Fischer JW, Phillips GE: A fence design for excluding elk without impeding other wildlife. Rangeland Ecology \& Management 60:529-532, 2007.

40. Williams ES, Yuill T, Artois M, Fischer J, Haigh SA: Emerging infectious diseases in wildlife. Rev Sci Tech 21:139-157, 2002.

41. Wobeser GA: Disease in Wild Animals, 2nd ed., pp. 53-82, 183340. Springer, Berlin, Germany, 2007.

42. Zanella G, Durand B, Hars J, Moutou F, Garin-Bastuji B, Duvauchelle A, Fermé M, Karoui C, Boschiroli ML: Mycobacterium bovis in wildlife in France. J Wildl Dis 44:99-108, 2008. 